\title{
Comparison of Miocene ambers of tropical Borneo paleoenvironments and potential extant plant
}

BERND R.T. SIMONEIT ${ }^{1}$, JUSTYNA SMOLAREKLACH $^{2}$, MAGDALENA GORYL ${ }^{3}$, MICHAŁ BUCHA ${ }^{2}$, MACIEJ RYBICKI ${ }^{2}$, LESZEK MARYNOWSKI ${ }^{2}$

${ }^{1}$ Department of Chemistry, Oregon State University, Corvallis, OR 97331, U.S.A.; simonebe@onid.orst.edu

${ }^{2}$ Institute of Earth Sciences, Faculty of Natural Sciences, University of Silesia, Bedzinska 60, Sosnowiec 41-200, Poland; justyna.smolarek-lach@us.edu.pl

${ }^{3}$ Institute of Geological Sciences, Polish Academy of Sciences, Senacka 1, 31-002 Kraków, Poland; magdalena.goryl@gmail.com

Fossil resins (ambers) occur commonly with Cenozoic coals and wood-bearing sedimentary rocks, less typical are in Mesozoic strata, and very rare in Upper Paleozoic deposits. The chemical composition of ambers is highly diverse, characterized by the occurrence of a variety of terpenoids including: mono-, sesqui-, di-, and triterpenoids. The direct analyses of its chemical constituents in total extracts using polar solvents permits the elucidation of unaltered natural products, which are characteristic of the source plants or paleobiome. At this time, comparatively little is known about the plant origins of fossil resins that formed in tropical climate. Here, we present the complex chemical characteristic, based on gas chromatography-mass spectrometry (GC-MS), of Miocene ambers from the tropical climate region of Kalimantan, Indonesia and their affinity to modern plants from that area. All examples of extant plant resins described here are comprised of only sesqui- and triterpenoids. The main producers of resins forming these Miocene ambers were angiosperms - probably resins of Shorea and less likely Hopea species. The key chemotaxonomic marker, present in the ambers and extant Shorea species, was asiatic acid. All samples were composed of sesquiterpenoids and triterpenoids in various proportions, without diterpenoids, characteristic for flowering plants. The sesquiterpenoids in the resins of both ambers and extant plants were primarily natural products with the cadinane skeleton. The triterpenoids of the extant resins of the Dipterocarpaceae and Miocene ambers were characterized by a prevalence of ursane over oleanane types. Polymerization of cadinoids in resins from Shorea species and in the ambers was not extensive. Based on the amber compositions we conclude that the maturity range of the Miocene deposits from Kalimantan is rather low, but differs depending on their location. 